\title{
Treatment of fracture dislocation of the femoral head using safe surgical hip dislocation: a case report.
}

\author{
Paa BAIDOO ${ }^{1}$, Kwasi Twumasi-Baah $\mathrm{Jnr}^{1}$, Kwadwo Anning ${ }^{2}$, Alex Assim², Emmanuel \\ Ayodeji ${ }^{2}$, and Senyo Gudugbe ${ }^{2}$ \\ ${ }^{1}$ Affiliation not available \\ ${ }^{2}$ Komfo Anokye Teaching Hospital
}

January 14, 2021

\begin{abstract}
We report the clinical and radiological outcomes of a 30-year-old female with femoral head fracture following a posterior hip dislocation. The patient was managed using safe surgical hip dislocation and reviewed the literature on Pipkin type I fractures.
\end{abstract}

Treatment of fracture dislocation of the femoral head using safe surgical hip dislocation: a case report.

Authors

Paa Kwesi Baidoo ${ }^{1}$, Kwasi Twumasi Baah $\mathrm{Jnr}^{1}$, Abu Anning ${ }^{1}$, Alex Osei Assim² ${ }^{2}$ Emmanuel Kafui Ayodeji ${ }^{2}$, Senyo Gudugbe ${ }^{1}$

${ }^{1}$ Directorate of Orthopedics and Trauma, Komfo Anokye Teaching Hospital, Kumasi, Ghana

${ }^{2}$ Department of Surgery, Komfo Anokye Teaching Hospital, Kumasi, Ghana

Corresponding author:

Paa Kwesi Baidoo

Directorate of Orthopedics and Trauma, Komfo Anokye Teaching Hospital, Kumasi, Ghana

Email: pakvandal@gmail.com

https://orcid.org/0000-0003-4028-1911

Abstract

We report the clinical and radiological outcomes of a 30-year-old female with femoral head fracture following a posterior hip dislocation. The patient was managed using safe surgical hip dislocation and reviewed the literature on Pipkin type I fractures.

Keywords: Pipkin, femoral head, fracture, surgical hip dislocation, outcome, complication

Funding: none

Introduction

Femoral head fractures are quite rare and may be associated with hip dislocations, femoral neck, and acetabular fractures ${ }^{1,2}$. The reported annual incidence is about 2 cases per million ${ }^{3}$. Since Birkett ${ }^{4}$ first descriptions of these fractures in 1869, there have been many case reports. Pipkin ${ }^{5}$ in 1957 recommended a classification system for femoral head fractures and this is widely used to this day. The classification divided these 
injuries into 4 types; type I. involves the non-weight bearing part of the femoral head, type II affects the weight-bearing part of the head of femur, type III may include either or both types I or II with femoral neck fracture, and type IV involves type I or II associated with acetabular fracture ${ }^{5}$.

Hip dislocations like any other joint dislocations are orthopedic emergencies and usually result from high energy injuries. The classical mechanism is from "dashboard injury" but may also result from sports injuries or fall from heights ${ }^{6}$. Femoral head fractures have traditionally been known to have poor functional outcomes and high complication rates especially avascular necrosis (AVN) and post-traumatic arthritis of the hip joint ${ }^{7-9}$. It is well documented that early reduction should be done under anesthesia and adequate muscle relaxation, stabilization, and rigid fixation to achieve stable and congruent joint thereby reducing potential complication rate ${ }^{1,6}$. The best surgical approach on whether to fix or excise the femoral head fragment however remains controversial ${ }^{2}$.

Many approaches have been proposed for the fixation of these fractures but the drawback is the limited exposure of the femoral head in all these approaches ${ }^{1,8}$. However, the current technique of safe surgical hip dislocation (SHD) as proposed by Ganz et al ${ }^{10}$ allows for complete exposure of the femoral head and acetabulum without interrupting the blood supply of the femoral head. We report our management of a patient with pipkin using the approach proposed by Ganz which conforms to the SCARE Criteria ${ }^{11}$.

Case Report

Our patient is a 30-year-old Ghanaian female who was an unrestrained backseat passenger in a saloon car that was involved in a head-on collision. The patient lost consciousness that lasted for about an hour after the accident. At presentation at the emergency department of the hospital, she had a Glasgow coma score (GCS) of 15/15. The patient sustained frontal scalp hematoma and multiple lacerations on the left lower limb. Her left lower limb was shortened, flexed at the hip, adducted, and internally rotated. There was no associated neurovascular deficit. Computerized tomography (CT) scan of the brain was normal and a pelvic x-ray showed posterior dislocation of the left hip associated with femoral head fracture (Figure 1). A diagnosed of posterior dislocation of the left hip (Pipkin type 1) was made.

An emergent closed reduction under general anesthesia was done at the emergency department. Following the reduction, the hip was found to be relatively unstable. Post reduction pelvic x-ray showed an incongruent and widened hip joint (Figure 2). A CT scan of the pelvis with 3D reconstruction showed a large femoral head fragment inferior to the fovea centralis that was not anatomically reduced (Figures 3a and 3b). An open anatomical reduction and internal fixation using safe surgical hip dislocation as described by Ganz ${ }^{10}$ was done 4 days after the initial. The delay was as a result of unavailability of Herbert screws at the time of presentation. Intra-operatively, the fragment was found to be viable (viability of the femoral head was confirmed by observing bleeding from the fragment following perforation using a $1.6 \mathrm{~mm}$ Kirschner wire) hence anatomical reduction was done followed by fixation of the fragment using two $2.7 \mathrm{~mm}$ subchondral headless cannulated screws (Herbert screws) on the posterio-inferior aspect of the head (Figure 4a and b). The labrum was found on inspection to be torn and was repaired using Vicryl 2 suture. The capsule was closed with Vicryl 2. The greater trochanter was fixed using two 3.5mm cortical screws (Figure 4c).

Postoperatively, the patient was kept non-weight bearing on crutches for 8 weeks and was put on $25 \mathrm{mg}$ indomethacin (trice daily for a month) as a prophylaxis against heterotopic ossification. At one-year followup, she had a painless hip with a full range of motion and there was no evidence of AVN of the femoral head (Figure 5a and 5b) or heterotopic ossification.

\section{Discussion}

The most important determinant of optimum outcome is the time between the dislocation and reduction of the hip joint. Epstein et $\mathrm{al}^{7}$ recommended that all traumatic hip dislocations should be managed as surgical emergencies and multiple attempts at closed reduction should be avoided to minimize the risk of AVN which has an incidence between $8 \%$ to $26 \%^{2}$. According to Epstein ${ }^{12}$ reduction within 24 hours lead to better outcome compared to when done after 24 hours. McMurtry et al ${ }^{13}$ further indicated that the risk of AVN 
of the femoral is small when reduction is done within 6 hours.

Pipkin I fractures can be managed either surgically or non-operatively depending on the fragment size and surgical expertise. In general, surgical management is recommended for types I and II fractures with large fragments especially those located at the weight bearing region of the head as well as all types III and $\mathrm{IV}^{14,15}$. Achieving optimal results is dependent on obtaining an anatomic reduction of the fragments, which is difficult with closed reduction. Henle et $\mathrm{al}^{9}$ recommended surgical treatment to improve the reduction if the gap between the fragments were more than $2 \mathrm{~mm}$ as only 1 in 12 patients in their series had anatomic reduction following closed manipulation.

The best surgical approach for Pipkin fractures remains controversial ${ }^{1,9,10}$. The Kocher-Langenbeck, SmithPeterson, and Watson Jones approaches or percutaneous fixation after a successful reduction have been used in managing these injuries albeit with limited exposure of the femoral head and acetabulum ${ }^{7,8,12}$. Safe SHD has been increasingly used in addressing head of femur fractures despite its technical challenges ${ }^{10,16}$. It enables full access to the whole acetabulum and femoral head, facilitates the anatomic reduction of the fragments, and also helps identify any chondral, subchondral, or labral tears which may not be seen using the other approaches ${ }^{1,2,10}$. Labral tears are found in up to $50 \%$ of patients and are associated with poor outcome $^{2}$. The functional outcome (in terms of pain and range of motion of the hip joint) of our patient was satisfactory probably because it was a Pipkin type I fracture. However the choice of safe SHD may have contributed to this outcome as the approach minimizes the risk of vascular injury to the head and the already traumatized soft tissue.

Conclusion

This case demonstrates the efficacy of safe surgical hip dislocation in managing femoral head fractures. The type of treatment and surgical approach should be guided by the fracture type and the associated injuries. Irrespective of the method or surgical approach however, we should always aim for anatomical reduction of the fragments while minimizing injury to the surrounding soft tissues.

Acknowledgements

None

Conflict of interest

None declared

Authors contribution

PKB, KTB, AA, AOA, EKA and SG performed the surgical procedure, followed up on the patient and prepared the manuscript.

Ethical approval

Written informed consent was obtained from the patient for publication of this case report and the associated images.

References

1 Gardner, M. J. et al. Surgical dislocation of the hip for fractures of the femoral head. J Orthop Trauma 19 , 334-342 (2005).

2 Gavaskar, A. S. \& Tummala, N. C. Ganz Surgical Dislocation of the Hip Is a Safe Technique for Operative Treatment of Pipkin Fractures. Results of a Prospective Trial. J Orthop Trauma 29 , 544-548, doi:10.1097/BOT.0000000000000399 (2015).

3 Kelly, P. J. \& Lipscomb, P. R. Primary vitallium-mold arthroplasty for posterior dislocation of the hip with fracture of the femoral head. The Journal of bone and joint surgery. American volume40-A , 675-680 (1958). 
4 Birkett, J. Description of a dislocation of the head of the femur, complicated with its fracture; with remarks by John Birkett (1815-1904). 1869. Clinical orthopaedics and related research , 4-6, doi:10.1097/00003086200008000-00002 (2000).

5 Pipkin, G. Treatment of grade IV fracture-dislocation of the hip. The Journal of bone and joint surgery. American volume 39-A , 1027-1042 passim (1957).

6 Ross, J. R. \& Gardner, M. J. Femoral head fractures. Current reviews in musculoskeletal medicine $\mathbf{5}$, 199-205, doi:10.1007/s12178-012-9129-8 (2012).

7 Epstein, H. C., Wiss, D. A. \& Cozen, L. Posterior fracture dislocation of the hip with fractures of the femoral head.Clinical orthopaedics and related research , 9-17 (1985).

8 Stannard, J. P., Harris, H. W., Volgas, D. A. \& Alonso, J. E. Functional outcome of patients with femoral head fractures associated with hip dislocations. Clinical orthopaedics and related research , 44-56, doi:10.1097/00003086-200008000-00008 (2000).

9 Henle, P., Kloen, P. \& Siebenrock, K. A. Femoral head injuries: Which treatment strategy can be recommended? Injury 38 , 478-488, doi:10.1016/j.injury.2007.01.023 (2007).

$10 \mathrm{Ganz}, \mathrm{R}$. et al. Surgical dislocation of the adult hip a technique with full access to the femoral head and acetabulum without the risk of avascular necrosis. The Journal of bone and joint surgery. British volume 83, 1119-1124, doi:10.1302/0301-620x.83b8.11964 (2001).

11 Agha, R. A. et al. The SCARE 2018 statement: Updating consensus Surgical CAse REport (SCARE) guidelines. Int J Surg60 , 132-136, doi:10.1016/j.ijsu.2018.10.028 (2018).

12 Epstein, H. C. Traumatic dislocations of the hip. Clinical orthopaedics and related research, 116-142, doi:10.1097/00003086-197305000-00011 (1973).

13 McMurtry, I. A. \& Quaile, A. Closed reduction of the traumatically dislocated hip: a new technique. Injury 32, 162-164, doi:10.1016/s0020-1383(00)00152-2 (2001).

14 Park, K. S., Lee, K. B., Na, B. R. \& Yoon, T. R. Clinical and radiographic outcomes of femoral head fractures: excision vs. fixation of fragment in Pipkin type I: what is the optimal choice for femoral head fracture? J Orthop Sci 20 , 702-707, doi:10.1007/s00776-015-0732-6 (2015).

15 Lin, D. et al. Emergent surgical reduction and fixation for Pipkin type I femoral fractures. Orthopedics 36 , 778-782, doi:10.3928/01477447-20130523-24 (2013).

16 Henriques, R. et al. Management of Pipkin Fractures Using a Safe Surgical Hip Dislocation. Case Rep Orthop 2019, 3526018, doi:10.1155/2019/3526018 (2019).

Figure legends

Figure 1

Pre-operative pelvic x-ray, AP, showing fracture dislocation of the left hip joint.

Figure 2

Post reduction pelvic x-rays showing widening of the left hip joint and retained fragment of the femoral head.

Figure $3 \mathrm{a}$ and $\mathrm{b}$

Post reduction axial C.T scan (3a) of the pelvis showing fracture of the femoral head with a non-anatomical reduction of the fragment and $3 \mathrm{D}$ reconstruction $(3 \mathrm{~b})$ showing femoral head fracture inferior to the fovea centralis (Pipkin I).

Figure $4 \mathrm{a}, \mathrm{b}$ and $\mathrm{c}$ 
Intra-operative image showing the large femoral head fragment (4a) and reduced fragment (4b) fixed with two $2.7 \mathrm{~mm}$ Herbert screws subchondrally and (4c)post-operative pelvic x-ray showing screw fixation of the greater trochanter.

Figure $5 \mathrm{a}$ and $\mathrm{b}$

Axial (5a) and sagittal C.T scans (5b) as well as AP pelvic x-ray at one year post injury showing healed fracture with no evidence of avascular necrosis.

\section{Hosted file}

Figure 1.pdf available at https://authorea.com/users/389535/articles/504124-treatment-offracture-dislocation-of-the-femoral-head-using-safe-surgical-hip-dislocation-a-casereport

\section{Hosted file}

Figure 2.pdf available at https://authorea.com/users/389535/articles/504124-treatment-offracture-dislocation-of-the-femoral-head-using-safe-surgical-hip-dislocation-a-casereport

\section{Hosted file}

Figure $3 a$ and b.pdf available at https://authorea.com/users/389535/articles/504124-treatmentof-fracture-dislocation-of-the-femoral-head-using-safe-surgical-hip-dislocation-a-casereport

\section{Hosted file}

Figure $4 \mathrm{a}$ and b.pdf available at https://authorea.com/users/389535/articles/504124-treatmentof-fracture-dislocation-of-the-femoral-head-using-safe-surgical-hip-dislocation-a-casereport

\section{Hosted file}

Figure 4c.pdf available at https://authorea.com/users/389535/articles/504124-treatment-offracture-dislocation-of-the-femoral-head-using-safe-surgical-hip-dislocation-a-casereport

\section{Hosted file}

Figure 5a and b.pdf available at https://authorea.com/users/389535/articles/504124-treatmentof-fracture-dislocation-of-the-femoral-head-using-safe-surgical-hip-dislocation-a-casereport 